in cases involving non-Europeans, where the group frequencies are not sufficiently well established, the percentage of possible fathers in the population is easily calculated. It is the Law Commission's view that a figure for possible fathers as low as 1 or $2 \%$ might be taken as evidence pointing to actual paternity. This figure agrees closely with Lord Willmer's acceptance of $2.27 \%$ alternative possible fathers as indicating the slight possibility of any father other than the husband. ${ }^{4}$ A cautious approach is needed here, for serologists frequently find the groups fitting very well with paternity until a final test rules out the possibility.

\section{Police Surgeons}

Police surgeons' work is often done at night, and much of it is unpleasant as well as difficult-it is not easy, for instance, to examine an aggressive drunk to exclude the presence of a head injury. So it is not surprising that in some areas the local police sergeant may need to contact 20 doctors before finding one willing to turn out in the middle of the night.

Negotiations have been going on for more than a year between local authorities and the B.M.A. in an attempt to reform the system, but these negotiations have reached deadlock. At its meeting on 20 November (Supplement, p. 41) the B.M.A. Council agreed to recommend that the British Medical Guild should advise police surgeons to resign their contracts and to negotiate new ones only if satisfactory terms are offered, and this has been done. There is no question, however, of doctors refusing to see or treat anyone who might be ill. They will refuse to perform examinations intended only to provide medical evidence for the police.

As medicine moves into an era when measurement is increasingly used to support clinical opinion it becomes more important that police surgeons should have a comprehensive knowledge of the procedures that have been developed in forensic science. Shortly before the Road Safety Bill ${ }^{1}$ became law the Home Office sent a circular to all chief constables and police authorities drawing their attention to the likelihood of " a considerable increase in the number of cases" of drivers suspected of drinking-driving offences, and recommending that each area should appoint designated police surgeons and deputies who would be familiar with the techniques and procedures required by the new law. ${ }^{2}$ The B.M.A. and the Police Surgeons' Association were agreed that the old haphazard system of multiple occasional police surgeons should be replaced by an arrangement whereby all parts of the country should have a designated surgeon or a deputy available at all times. In 1967 the Police Surgeons' Association prepared a memorandum ${ }^{3}$ setting out proposals to modernize the system and to give the police an efficient service, and the memorandum was approved by the Annual Representative Meeting later that year. ${ }^{4}$ Since that time negotiations have been in progress between the B.M.A. and the Local Authorities Association. Agreement was virtually reached on a scale of fees for services, but the negotiations have broken down on the question of the retaining fee.

\footnotetext{
1 Road Safety Bill (179), 1967. H.M.S.O.

2 Brit. med. f., 1967, 2, 67.

s Brit. med. F. Suppl., 1967, 2, 104.

- Brit. med. f. Suppl., 1967, 3, 95.
}

The B.M.A. and the Police Surgeons' Association suggested that one police surgeon could cover a population of about 100,000 (with exceptions in areas of unusual population density). Such an area could have one surgeon available, for, say, 9 days in 14 and a deputy available for the other 5 . The suggested retaining fee, to be shared by the two doctors, was $£ 500$ a year; but any doctor who earned more than $£ 500$ a year in fees from the police would have his retaining fee reduced on a sliding scale. The figure corresponds with the fee set by the Review Body for out-of-hours cover by a general practitioner. Should any local authority insist on more police surgeons being retained the B.M.A. was willing for the retaining fee to be further divided on a time basis. But the Local Authorities Association has refused to agree to this scheme. Apparently it prefers to keep the system by which several doctors are appointed as police surgeons but no one doctor guarantees to be available at any particular time.

This is an occasion on which the public should give doctors full support. Public interest requires that a person in police custody on whom a medical opinion is required should be seen as quickly as possible by a doctor with experience in forensic science. Delay or inexperience can be dangerous for the arrested person and can lead to injustice. Police surgeons are being asked by the Guild not to make resignations effective until after the New Year. By then the Local Authorities Association should have seen the merits of their case.

\section{Voluntary Restriction of Amphetamines}

Amphetamine and amphetamine-like drugs can produce acute toxic states, with symptoms of overstimulation of the sympathetic and central nervous systems. ${ }^{1}$ They can also produce various degrees of dependence ranging from mild habituation to a strong compulsion to take the drugs indefinitely. ${ }^{2}$ More severe cases of dependence show all the characteristics of other types of addiction. The development of tolerance can lead to a need for increasing doses, with the consequence of undesirable effects such as insomnia, anorexia, and abnormal behaviour. ${ }^{3}$ Amphetamines may produce transitory psychotic reactions, clinically indistinguishable from paranoid schizophrenia. ${ }^{4}$ Those addicted may harm society through neglect of

1 Kalant, O. J., The Amphetamines: Toxicity and Addiction. 1966.

${ }^{2}$ Connell, P. H., Proc. roy. Soc. Med., 1968, 61, 178.

3 Kramer, J. C., Fischman, V. S., and Littlefield, D. C., f. Amer. med. Ass., 1967, 201, 305.

- Connell, P. H., Amphetamine Psychosis. Maudsley Monograph No. 5. 1958. London.

S Nagahama, M., Bull. Narcot., 1968, 20, No. 3, 19.

- Goldberg, L., Bull. Narcot., 1968, 20, No. 1, 1 .

- Goldberg, L., Bull. Narcot., 1968, 20, No. 2, 9.

Goldberg, L., Bull. Ne Chief Medical Officer of the Ministry of Health for the Year 1954, Part 2, p. 109. 1955. H.M.S.O.

- Drug Addiction: Report of the Interdepartmental Committee. 1961 H.M.S.O.

10 Annual Report of the Chief Medical Officer of the Ministry of Health for the Year 1967. 1968. H.M.S.O.

1 f. Amer. med. Ass., 1966, 197, 1023.

12 Report of the Working Party on Amphetamine Preparations, 1968. British Medical Association, London.

13 Drug Addiction: Second Report of the Interdepartmental Committee. 1965. H.M.S.O.

14 Hood, H., and Wade, O. L., Lancet, 1968, 2, 96. 
family and work, financial irresponsibility, and other antisocial behaviour..$^{5-7}$

In Japan from 1946 to 1954 there was a widespread epidemic of misuse of amphetamines, with over 1,000,000 estimated stimulant addicts at one time, ${ }^{5}$ and there has recently been a similar epidemic of misuse of the drug by intravenous injection in Sweden, leading eventually in both countries to amphetamines being generally withdrawn. ${ }^{5-7}$ In view of recent increases of similar types of misuse in Great Britain it has become necessary to review the place of these drugs in present-day medical practice.

The Ministry of Health's annual report for 1954 included the statement "The drugs of this group [amphetamines] have the advantage of being relatively non-toxic, addiction to them is rare, and there are no serious ill effects." Kingdom in $19592.5 \%$ of all prescriptions $(5,600,000$ out of 214 million) were for stimulants and appetite suppressants. ${ }^{9}$ In 1967 there were 4.8 million, $1.8 \%$ of all prescriptions. ${ }^{10}$ In the United States the Food and Drug Administration calculated there were 25-50 doses available on average for every man, woman, and child in the country in 1962. ${ }^{11}$ In view of recent increasing evidence of misuse of this group of drugs a working party of the B.M.A.'s Committee on Medical Science, Education, and Research has been reconsidering their legitimate uses. ${ }^{12}$ Its report, whose conclusions are summarized this week in the B.M.F. (page 572) was approved by the Council at its last meeting for transmission to the Interdepartmental Standing Advisory Committee on Drug Dependence. It confirms a recurring pattern with new drugs affecting the central nervous system. Most are at first thought to be valuable, non-addictive, and reasonably safe. Later they are found to be less valuable, addictive, and potentially dangerous.

The working party concludes that amphetamines have a very small part to play in legitimate medical practice; they should rarely be prescribed and should be subject to strict voluntary control. It recommends that amphetamine and amphetamine-like compounds should now only be prescribed for those conditions for which no reasonable alternative exists, such as narcolepsy, or is part of the therapy of those patients already dependent on these drugs. Specifically it recommends that the drugs should be avoided so far as possible in the treatment of obesity (suggesting the possible substitution of fenfluramine) and depression, and that their use in other conditions should be discontinued. The treatment of patients already dependent on small doses should be reconsidered individually. It is suggested that patients dependent on large doses will require special psychiatric treatment similar to that provided for heroin-dependent patients.

To restrict the availability of amphetamines the working party suggests that manufacturers, pharmacists, nurses, and doctors should voluntarily take the same precautions and keep the same records as they already do for those drugs covered by Part 1 of the Schedule of the Dangerous Drugs Act. Finally, it recommends that the manufacturers should be encouraged to produce amphetamine compounds intended for oral use in a form from which the active ingredient cannot easily be extracted for intravenous use. It ends by stating that if voluntary control does not succeed restrictive legislation will be inevitable. The working party has also recommended a new system of defining the use, misuse, and abuse of drugs, but there may be some difficulty in achieving a general acceptance of it because the American Council on
Alcoholism and Addiction and Council on Mental Health define them differently. ${ }^{11}$

A voluntary system of control depends on co-operation from all members of the medical profession. Though the working party does not consider the possibility that the control might break down or be incomplete, the question needs examination in the light of experience gained by the second Interdepartmental Committe ${ }^{13}$ and the fact that a small minority of doctors have been prescribing disproportionate amounts of amphetamines. ${ }^{14}$ This aspect of prescribing might be considered by the Standing Advisory Committee on Drug Dependence.

\section{Pancreatitis in Children on Steroid Therapy}

Among the serious complications of long-term treatment with steroids pancreatitis is probably one of the most ominous but fortunately also one of the rarest. None the less T. A. Riemenschneider and his colleagues ${ }^{1}$ have recently reported six cases. In reviewing the literature they collected a further 15 instances of the syndrome over the past ten years, the first cases having been reported simultaneously from England? and Poland. ${ }^{3}$ Of the 21 cases only 4 seem to have recovered ; but earlier recognition of the calamity may alter the prognosis if treatment follows rapidly on the diagnosis.

Pancreatitis should be considered in every child on steroid therapy who presents a picture of an acute abdominal emergency. The patient appears pale and anxious, with severe abdominal pain, nausea, and vomiting. The abdomen is distended and of a doughy consistency. Paralytic ileus and ascites may be additional features. Peripheral circulatory collapse and renal failure are more common in adults but have been observed in children.

The laboratory findings helpful in making the diagnosis are a significant elevation of serum amylase, hyperglycaemia, leukocytosis, glycosuria, and albuminuria. The peritoneal fluid may contain high levels of pancreatic amylase also and minute fat globules. The serum calcium level, initially normal, may fall on the second or third day owing to calcium precipitation with fatty acids in the mesenteric and peripancreatic tissues.

Pancreatitis was known in childhood before the introduction of steroids. B. S. Schultze $e^{4}$ was able to collect from the literature 125 instances of pancreatitis in the paediatric age range, of which six only had received steroid treatment. The largest number fell aetiologically into the "idiopathic" group, followed by those ascribed to metabolic and toxic factors and trauma. Infection and obstruction of the pancreatic ducts or the ampulla of Vater seemed to be of equal importance. Schultze's cases did not include the 15 patients reported by H. W. Hendren and his colleagues ${ }^{5}$ nor the three reported by $\mathrm{B}$. Wolman, ${ }^{6}$ none of whom had received steroids. All

\footnotetext{
1 Riemenschneider, T. A., Wilson, J. F., and Vernier, R. L., Pediatrics, $1968,41,428$.

2 Baar, H. S., and Wolff, O. H., Lancet, 1957, 1, 812

3 Marczynska-Robowska, M., Lancet, 1957, 1, 815.

- Schultze, B. S., Handbuch d. Kinderhk., 1965, Vol. 4, p. 1195, H. Opitz and F. Schmid. Berlin, Heidelberg, and New York.

Hendren, W. H., Greep, J. M., and Patton, A. S., Arch. Dis. Childh., $1965,40,132$.

6 Wolman, B., Brit. med. F., 1962, 1, 1591.
} 